\title{
Impact of Behavioral Biases on Investment Decision Making with Moderat- ing Role of Financial Literacy
}

\author{
Rizwan Khalid ${ }^{1}$, Muhammad Usman Javed ${ }^{* 2}$, Khurram Shahzad ${ }^{3}$ \\ Riphah International University, Islamabad, Pakistan
}

\begin{abstract}
The objective of this study is to examine the Impact of Overconfidence bias and Herding bias on Investment Decision Making with Moderating Role of Financial Literacy. The population was Investor, Employee and Graduate Student. A sample of 200 was selected using convenience technique. Data were collected through structure questionnaire adopted from different papers. Correlation and Regression analysis were performed to examine the result. The Results show that overconfidence bias and herding bias have a positive impact on investment decision making and Financial Literacy has positive impact on investment decision making. Based on the results and discussions of the study findings as well as the limitations, theoretical and practical implications of the study have been provided.
\end{abstract}

\section{Introduction}

Standard Finance, also known as Traditional Finance, is based on the number of theories or principles and also several studies conducted in many different countries consider that the investor is rational because he makes the decision to invest based on all available information. Behavioral finance is the new field that seeks to combine the theory of behavior (aspirations, cognition, and emotions) and cognitive psychology. It explains why investors make rational financial decisions in the stock market.

Investment is not an easy process, since the assumption is that investors always expect to maximize returns, although not all investors are so rational (Sukanya and Thimmarayappa, 2015). The investment is mainly influenced by a large number of psychological and emotional factors (Sukanya and Thimmarayappa, 2015).

There are so many factors that affect the behavior of investor in stock market in many ways; some of the factors are investment time period, other investor/participant standard performance and the presence of instability and conjecture in the stock markets (Chang et al., 2009). Some investors invest in stock market with some planning and some invest without planning in order to get more interest that will make them rich overnight. There are number of options available to them either to buy a stock of company based on available essential information or on the suggestion of broker or other investors. On the other hand investors invest on the basis of their available information, finan-

*Corresponding author.

Email: usman.javed@cust.edu.pk cial resources and time period (Muhammad and Abdullah, 2009).

Pompian (2012) reported that behavioral biases refer to the propensity to make decision that result in unwise financial decisions due to cognitive decline and/or emotional impact. There are so many prejudices in human psychology (Shefrin et al., 2010). Lin et al. (2011) suggested that lack of technical expertise are the result of behavioral biases and he thinks that investors can make better investment decision based on their ability and expertise. According to him, investors rational decision making is influenced by number of behavioral biases such as disposition effect, herding bias, and overconfidence bias and so on. These biases affect individuals the way they often do it in a foolish way, often ignoring common ideas about risk aversion and making speculations and predictions they can anticipate (Patel and Sewell, 2015).

Investors profile determines each investment statement and behavioral biases manage through effective ways (Pompian, 2012). Financial literacy also affect investor decision making Financial literacy is the ability to understand how money works in the world: how someone can earn or make it, how that person manages it, how he/she invests it (turn it into more) and how that person donates it to help others (Giesler and Veresiu, 2014). Financial literacy with respect to gender, work experience, class and education is different.

Although there are many reviewed studies that contribute to the development of behavioral preferences among investors, most of these studies have focused on the developed countries, such as the United 
States, the United Kingdom and Europe. Behavioral biases affect more Asian investors as contrast to European investors (Yates et al., 1997). Some studies have been carried out in Pakistan to develop the effect of behavioral biases in investment decision making using other variables as moderating or mediating variables and their results contributing to knowledge. Financial literacy is an important factor that is no longer debated in Pakistan, where most people do not have financial information.

There are few researches conducted on this issue that indicate financial literacy is extensive and people have lack of information, even regarding basic economic principles (Lusardi and Mitchell, 2011), National Council of Economic Education (NCEE, 2005), and (Hilgert et al., 2003).

In Pakistan, many people do not have financial knowledge because the investor has a lack of financial knowledge and does not have the necessary technical skills to invest in stocks, and the intermediary takes advantage of this deficiency to manipulate investors. So there is a need to study the individual investor behavior that helps to establish financial counseling services and establish policies for effective and secure financial systems.

The purpose of this study is to fill the gap in literature analyzing the situation and providing empirical evidence on the relationship between behavioral biases and investment decision making with the moderating role of financial education. Another objective of the study, in an unstable situation in Pakistan, is how investors behave in their investment decisions and how such behavior affects the performance of investors.

\section{Literature Review}

\subsection{Investment Decision}

Efficient market is the market where average returns cannot be greater than what are warranted for its risk despite whatever investment strategy is applied (Barberis and Thaler, 2003). The concept of behavioral finance expanded in the mid of 1980s (Shefrin and Statman, 1985). This is a new field where psychology combined with theories of traditional finance that explained in a better way of human irrational financial decision (Shefrin, 2002). Investment decision can be improved or easily understood by investor when the concept of psychology was introduced in traditional finance. It also helps the economist and financial decision takers to predict the unforeseen hurdles and occasions.

The decision making process is prescribed as the definition of an objective, the exploration of an alternative, the realization of a cost-benefit analysis and, ultimately, the choice of the lowest-cost option. Mod- ern economist assumes that there are two rational ways either people make decisions depending on expected utility theory and fair forecasting of future. But some economist stated that rational decision making of people is not acceptable. In the era of Milton Friedman, leading economist accentually suggested asset prices determined by rational investor. According to him financial market can be better defined with the introduction of human. With the passage of time, theory improved by behavioral finance by analyzing the behavior of human in financial market.

There are many factors such as investor demographic factor, investor types and level of risk tolerance that help the investor regarding financial decision making (Harikanth and Pragathi, 2012). Investment decisions have become very important because, the main objective of an investor is to make a good decision and earn maximum profits. But some investors rely on their personal judgment while others make decisions based on education and evidence.

\subsection{Overconfidence Bias and Investment Decision Making}

Another measure of risk is when people consider themselves better and superior relative to others (Larrick et al., 2007). Sometimes people over value their ability and sometimes undermine it (Malcolm S, Forbes). Investors overestimate their skills and abilities and underestimate the control of events. The overconfidence bias leads to market inefficiency due to erroneous pricing and excessive instability (Khurshid, 2012). Those investors, who are overconfident, invest more excessively in market because they do not have an idea of financial market and lack of information (Fuertes et al., 2014). Portfolio of that investor will always be less diversified. There are two main implications of overconfidence with respect to the investor's point of view, one is the omission to generalize information and the other is to do additional operations because of this failure (Shefrin and Statman, 2000).

Overconfidence is a well-established and common misconception that makes people trust on their knowledge and skills too much, and ignores the risk associated with investing. Studies in this area have explained how overconfidence skews excessive rational influences the behavior of decision making. Overconfidence bias positively affects the relationship of investor type and their decision (Zaidi and Tauni, 2012). In Pakistan investor decision making is strongly affect by overconfidence bias (Khurshid, 2012).

H1. Overconfidence bias has positive and significant impact on investment decision making. 


\subsection{Herding Bias and Investment Decision Making}

Herd behavior describes how individuals in a group can act collectively without centralized direction (Braha, 2012). Herding refers to the situation where rational people begin to behave irrationally to imitate the judgments of others while making decisions. There can be many reasons why herd behavior is exposed in different types of investors. Rational decision-making is based on the logical consistency of decision-making rather than the form; therefore, in decision making human emotions and intuitions play an important role. Simple way as rational choice is to select the preference from ranking (Samuelson and Zeckhauser, 1988).

Under the certain or uncertain condition, preference affects the decision of investor alternative according to rational choice model. Institutional investors have less graze pasture as compared to individual investor (Lee et al., 2002). In this age of uncertainty, it is better to copy other information and transmit it, so basically investors do the same, and someone follow the managers of the company when they sell shares and then to invest and when they buy weak stocks and with less educated investor I also do the same (Persaud, 2000).

The herding bias is when the investor follows other investors in making investment decisions, therefore, these results confirm that investment decision making is positively influenced by herding bias. Malik and Elahi (2014) claimed that investment decision is positively influenced by herding bias. In addition, some significant studies conducted on herding bias that affect the investment decision making (Grinblatt et al., 1995; Lakonishok et al., 1992; Wermers, 1999).

H2. Herding bias has significantly and positively affects the investment decision making.

\subsection{Financial Literacy and Investment De- cision}

Knowledge of basic economic and financial concepts, as well as the ability to use that knowledge and other financial skills to manage financial resources is effective for a lifetime of financial well-being (Hung et al., 2009). Financial literacy is the ability to understand how money works in the world, how human beings can earn or make money and their ability to manage it in effective way to get more returns from investment and sharing with others (Giesler and Veresiu, 2014). Financial Literacy refers with respect to demographic, education and work experience. Men have greater financial knowledge with respect to women and the same case in the remaining cases more work experience, more education and upper class rank have more financial knowledge compared to less work experience, less education and lower class rank.

Personal confidence and context significantly affect the investment decision of investor and the availability of financial information play a vital role in it (Widdowson et al., 2007). People of USA have greater financial literacy as compared to Asian countries (Chen and Volpe, 1998). There is a significant relationship between financial literacy and monetary amassing because people who have information about how to take an advantage of the equity surplus on investment. The availability of financial knowledge is an important factor that affects the investment decision (Merikas et al., 2003). To invest profitably, financial literacy should be improved (Agnew and Szykman, 2005). However there are different studies that examined that financial literacy is important and affect the investment decision positively.

H3. Financial literacy has significant and positive impact on investment decision making.

\subsection{Financial Literacy as moderating role on Behavioral biases and Investment decision}

As mentioned above, it is crucial to analyze behavioral biases and financial education to understand the real behavior of investors. Many studies show that both financial education and behavioral prejudices affect the behavior of investors. However, the relationship between these two concepts, which has a crucial role in financial decisions and the behavior of investors, has not been investigated in depth. There are several academic works in the field of cognitive ability and they are more likely to suffer biases and make investment mistakes (Bucher-Koenen and Ziegelmeyer, 2011).

There are several studies on behavioral biases and financial literacy that show different results with respect to the relationship between financial knowledge and behavioral biases that may be due to several factors. With reference to the relationship between the level of financial knowledge and investment decisions, it has been observed that highly literate investors prefer and use different techniques when making an investment decision than investors with low literacy. Highly literate investors prefer to use financial publications, while low literacy investors convey more about the advice of family members, friends and brokers. Because of this, investors show above all behavioral bias because they were illiterate, so they could not make decisions and do the same as other investors, when other investors sell the shares they sell when they look for little benefit in stock. Discard it and do not wait for further increase in the price, since they show excess confidence while they collect the actions and make wrong 
decisions (Hassan Al-Tamimi and Anood Bin Kalli, 2009).

H4. Financial Literacy has Moderating role in relationship between overconfidence bias and investment decision.

H5. Financial Literacy has Moderating role in relationship between herding bias and investment decision.

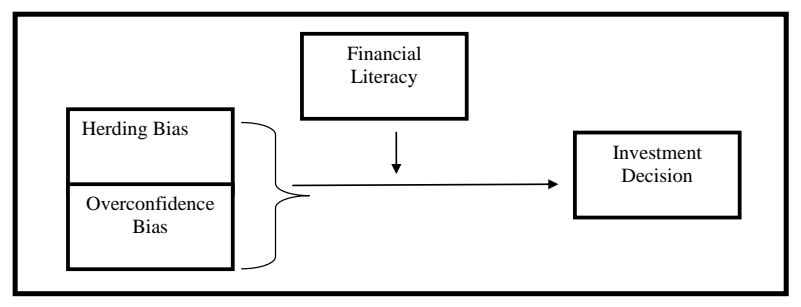

Figure 1: Conceptual Framework

\section{Methodology}

This section contains the complete research design about population, sample size and sampling producer, data collection technique and analysis of data.

\subsection{Sample and Data Collection}

The purpose of this study to review the impact of overconfidence bias and herding bias on investment decision making with the impact of financial literacy as moderating role. In order to achieve the above objective quantitative method is used for data analysis. The population was Investors, Employees and Graduate Students who invested in Islamabad stock Exchange. The study was the cross sectional study in which data were collected once across a population through sampling. Our research was a quantitative research in which we have done non probability sampling. Structure questionnaire was used by using convenience sampling technique, because through this technique researcher is able to gather a large amount of information easily at very low cost. The respondents participated voluntarily and were ensured that their answers will be confidential and will only be used for this investigation. Rea and Parker (2005) proposed that with a margin of error of $5 \%$ and a confidence level of $95 \%$, a total of 200 sample sizes were selected and the questionnaires distributed. Out of the 200 questionnaires distributed, 168 were received and 19 questionnaires were filled out incorrectly and 149 were usable for this investigation. Then, the rate of respondents is $75 \%$. The questionnaires were distributed by hand among different investors, brokerage houses and organizations, and some users collected online data that had access to the Internet.
As mentioned above, the total response of the sample size was 149 . One of the main portion of the sample, the male were 123 (82.3\% of the total sample size) and 26 were women, which was $17.4 \%$. $55.7 \%$ of respondents who were young and between 18 and 25 years old. $34.8 \%$ of the respondents who were between 26 and 35 years old and only $9.5 \%$ fall in the section from 36 to 45 years. As the majority fall between 18 and 25 years, most of the respondents were not married, was $69 \%$ of the total sample size and $30.6 \%$ of the respondents were married and only $0.6 \%$ were divorced. $55.1 \%$ of the total sample had a master's degree. $3.2 \%$ had a Ph.D. degree. 57\% of the participants were those who took stock courses, while the rest of $43 \%$ answered that they did not have a stock market. $34.1 \%$ of the participants had investment less than of Rs. 2 lac, 32.3\% had more than Rs. 2 lac but below Rs. 4 lac, 22.8\% had more than Rs. 4 lac but less than Rs. 10 lac, $4.4 \%$ had more than Rs. 20 lac but below Rs. 30 lac, 3.8\% had more than Rs. 30 lac and only $0.6 \%$ had more than Rs. 10 lac but below Rs. Investment of 20 lac in 2017.

\subsection{Measures}

A structure questionnaire composed of five main parts was used to collect the necessary data. The first four sections were related to our main study that explains the effect of two independent variables: herding bias and overconfidence bias, a dependent variable that was an investment decision, while financial literacy plays a moderating role in this study. The last section recognizes the age, marital status, education, income, experience, and current level of investment as demographic characteristic of respondent. The first four sections of the questionnaires contain nineteen (19) items. The five-point Likert scale was used to measure the relationship between dependent and independent variable where $1=$ totally disagree and $5=$ for totally agree according to the first 10 questions. For the next 9 questions, four options were given to accept and reject, and the results were being finalized on this basis.

Out of these nineteen (19) items that were used in the questionnaire, the dependent variable investment decision scale has 3 items adopted from Le-Phuoc et al. (2011). A sample element was "You feel satisfied with your investment decisions in the last year (including the sale, purchase, selection of shares and the decision of the volumes of shares)". The scale contained 7 items of the first independent variable, which was the herding bias, was adopted as suggested by Kengatharan and Kengatharan (2014). A sample of elements was "The decisions of other investors to buy and sell shares have an impact on their investment decisions." The last independent variable scale was on the overconfidence bias that had been adopted from (Pompian, 2012) and an article on the sample of this scale was "How much control do you think you have in choosing investments 
that will exceed the market"? And the scale for financial literacy as the moderator was adopted from Lusardi and Mitchell (2011) and a sample element of this scale was "Suppose you have Rs.100 in a savings account and the interest rate is $2 \%$ per annum. After 5 years, how much do you think you would have in the account if you left the money to grow?

In order to check the internal consistency between factor reliability analysis was used and measured with the help of Cronbach alpha. It is used as reliability to distinguish the relationship of different factor from each other. The upper scale 5 is considered an acceptable measure of reliability analysis. In our study we had 4 different variables with 28 elements. The Cronbach's alpha of all these variables was above 6, which means that there is strong internal reliability between the elements. For 3 investment decision points, the scale was observed .748, for 7 items of herding bias was .635 , for 3 articles of financial education was .92 and the rest of 6 articles belonged to overconfidence bias observed for these items was 0.773 .

\subsection{Control Variable}

The current study used some control variables related to the demographic data of the investors such as gender, age, income, and investment of the current year, investment of the previous year and duration of the visit to the stock market as a control variable when performing the test of regression. These variables were found from ANOVA since we observed $\mathrm{P}<.05$, so it suggests a significant effect of these variables in independent and dependent variables.

\section{Results}

Table 4.1 shows mean values, standard deviations and Pearson correlations between variables studied. Mean and standard deviation of herding bias is 3.20 and 0.247 and, Over-confidence bias is 2.53 and 0.167, Investment decision is 4.19 and 0.649 and financial literacy is 1.93 and 0.259 . Pearson's correlation is used to describe the relationship between independent variables (herding bias, disposition effect and overconfidence bias), moderator financial literacy and dependent variable investment decision.

\subsection{Regression Analysis}

Table 4.2 explains the effect of the independent variable (over-confidence bias and herding bias) with the moderator (financial literacy) on the dependent variable (investment decision-making). We performed different linear regression analyses to test the hypotheses. For this purpose, table 4.2 is divided into three steps. In the first step, gender, age, income, total time dedicated to the stock market, investment for the current year and investment from the previous year were entered as control variables. In step 2, the result shows that there is a positive effect of the overconfidence bias in investment decision making $\left(\beta=2.09{ }^{*} \mathrm{p}<.05\right)$. Hypothesis 1 (Positive and significant impact of overconfidence on investment decision making) is statistically significant. Hypothesis 2 (Investment decision making has positively and significantly impact by herding bias) is not compatible because the result shows a positive impact of herding bias on investment decision making but that relationship is non-significant $\left(\beta=0.01^{* *}, \mathrm{P}>\right.$ $.05)$.

The result also shows that financial literacy has a positive impact on investment decision making but is non-significant $\left(\beta=0.34^{* *} \mathrm{p}>.05\right)$ and therefore hypothesis 3 (Financial literacy has a significant and positive impact on making investment decisions) has been rejected. In step 3, it is shown that hypothesis 4, i.e. Financial Literacy plays a moderating role in the relationship between the over-confidence bias and the investment decision was rejected because $\beta=1.10 * *, \mathrm{P}>.05$, but hypothesis 5 , i.e. Financial Literacy plays a moderating role in the relationship between herding bias and investment decision was accepted because there is a positive and significant impact, i.e. $\beta=2.08 * p<.05$.

The moderation graph shows that when investor was highly literate about financial theories then he shows more herding bias as compared to illiterate investor. Therefore, it could be concluded that financial literacy has a positive relation with herding bias, while making any investment decision regarding the stock picking or disposition of stock.

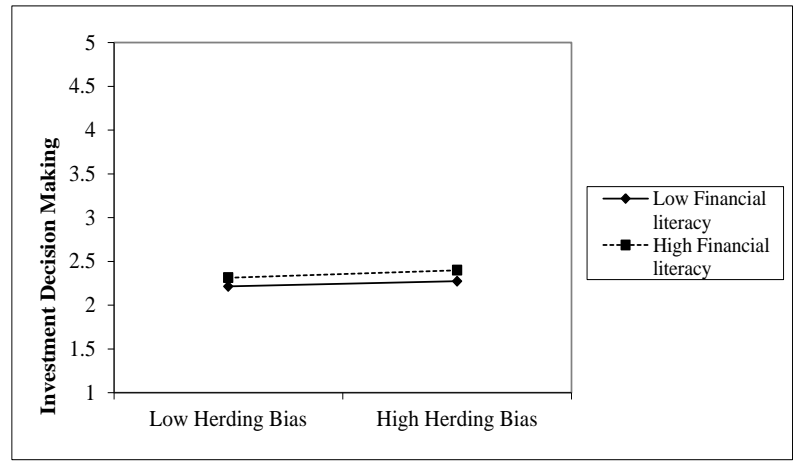

Figure 2:

\section{Discussion}

This study is done to review the role of herding bias and overconfidence bias in investment decision and moderating role as financial literacy. If we see with the view of theories of traditional finance then we conclude that investors make decision after assessing and exam- 
Table 4.1: Mean, SD, Correlation \& Reliability

\begin{tabular}{lcccccc}
\hline & Mean & S.D & $\mathbf{1}$ & $\mathbf{2}$ & $\mathbf{3}$ & $\mathbf{4}$ \\
\hline 1. HB & 3.20 & .247 & - & & & \\
2. OCB & 2.53 & .167 & 0.116 & - & & \\
3. ID & 4.19 & .649 & -0.207 & 0.280 & - & \\
4. F1 & 1.93 & .259 & 0.000 & -0.129 & 0.037 & - \\
\hline
\end{tabular}

Note. $N=149$; alpha reliabilities are presented in parentheses. $\mathrm{HB}=$ Herding Bias, $\mathrm{OCB}=\mathrm{Over}$ confidence bias, ID=Investment Decision, FL=Financial Literacy. ${ }^{*} p<.05 .{ }^{* *} p>05$.

Table 4.2: Result of Regression Analysis

\begin{tabular}{lccc}
\hline Predictors & \multicolumn{3}{c}{ Investment Decision Making } \\
Step 1 & $\beta$ & $R^{2}$ & $\Delta R^{2}$ \\
\hline Control Variable & & $0.002^{* *}$ & $0.002^{* *}$ \\
Step 2 & & & \\
Overconfidence Bias & $2.09^{*}$ & $0.470^{*}$ & $0.468^{*}$ \\
Herding Bias & $0.01^{* *}$ & & \\
Financial Literacy & $0.34^{* *}$ & & \\
Step 3 & & & \\
OCBxFL & $1.10^{* *}$ & & \\
HBxFL & $2.08^{*}$ & $0.513^{*}$ & $0.43^{*}$ \\
\hline
\end{tabular}

Note: $n=158, H E=$ Herding Bias, DE= Disposition Effect, $F L=$ Financial Literacy and $\mathrm{O}=$ Overconfidence bias. Control variables were Gender, Age, Income, Market Visit, Investment C, Investment $P^{*}<.05$ and $p^{* *}>.05$.

ining all the available information relating to the stock and after that they make investment and take advantage of their wealth and utility. However, behavioral finance totally opposes these theories and recommends that it is impractical that markets are perfectly normal and there is no concept of strong form of efficiency in market where all investors have the same information and they all are highly educated; making decision on the basis of experience, qualification. So, behavioral finance identified some psychological biases and their impact on investor decision making.

First hypothesis of this study stated that overconfidence bias has significant and positive effect on investment decision making and results significantly supported the hypothesis. Studies in this area have explained how overconfidence bias, excessive rational influence Decision-making behavior. Overconfidence bias positively affects the relationship of investor type and their decision (Zaidi and Tauni, 2012). In Pakistan investor decision making is strongly effect by overconfidence bias (Khurshid, 2012).

Second hypothesis stated that Herding bias has significant and positive impact on investment decision making, which was rejected based on regression results. The herding bias occurs when the investor fol- lows other investors in making investment decisions, therefore, the results are not in line with past study that investment decision making is positively influenced by herding bias. Malik and Elahi (2014) claimed that investment decision is positively influenced by herding bias. In addition, some significant studies (Grinblatt et al., 1995; Lakonishok et al., 1992; Wermers, 1999) on the behavior of the herd in investment decision-making have been carried out.

The third hypothesis is that financial literacy has a significant and positive impact on investment decision making and that it is not statistically significant, so the hypothesis is not supported. Effective decisions are made taking into account the possible financial consequences they can bring (Widdowson et al., 2007). Merikas et al. (2003) postulated that the availability of financial information is a significant variable that influences investment decisions. To invest successfully, financial education must be improved Agnew and Szykman (2005). However, there are different studies that examined that financial education has importance and positive influence on the investment decision.

The fourth hypothesis is that financial literacy moderates the relationship between the over-confidence bias and the investment decision, and the result is in- 
significant, so the hypothesis is not supported. Furthermore, hypothesis five stated that financial literacy moderates the relationship between herding bias and investment decision, and the hypothesis is supported by its statistical significance. There are several studies on behavioral biases and financial literacy that show different results with respect to the relationship between financial knowledge and behavioral biases that may be due to several factors. With reference to the relationship between the level of financial knowledge and investment decisions, it has been observed that highly literate investors prefer and use different techniques when making an investment decision than investors with low literacy. Highly literate investors prefer to use financial publications, while low literacy investors rely more on the advice of family members, friends and brokers. Because of this, investors show above all behavioral bias because they were illiterate, so they could not make decisions and do the same as other investors when other investors sell the shares they sell when they look for little benefit in stock. Discard it and do not wait for further increase in the price, since they show excess confidence while they collect the actions and make wrong decisions (Hassan Al-Tamimi and Anood Bin Kalli, 2009).

\subsection{Practical Implication}

On the basis of above research finding, the research brings a number of recommendations for managers and investor who invest in stock exchange. The study recommended that, in order to overcome excessive optimism behavioral biases that affect the frequency of investment in the stock market, need to conduct training programs and seminar that create awareness of investors and the capability to recognize and protect against such prejudices leading to poor investment options should be offered to potential and existing individual investors. The study also recommends that individual investors seek the advice of brokers / fund managers that have more experience in this field, to advise them in terms of guaranteeing certain security that the investor wants to invest.

\subsection{Limitation}

Time was main the constraint while conducting this research. The study was undertaken within specific academic timelines as the research study was projected to fulfill academic course work requirements. This study was organized through survey questionnaire that was always condemned due to general problems. Respondent may feel hesitate in their response because structure questionnaire was used for data collection that can lead to incorrect results.

\subsection{Direction for Future Research}

Quantitative research method was used for data collection, however many qualitative methods can also be used to better understand these problems. Qualitative research methodologies can better capture investor behavior. Therefore, in future research studies, there is a need to include qualitative research method. There is some potential of including some other variables in future research, such as culture dimensions, personality traits and investor types as independent variable, dependent variable, moderating variable and mediating variable in order to better understand financial decision making. This study focused on short-term investment decisions on the stock market, while there are many other types of financial decisions such as financing decisions, investments in other sectors of the economy. Therefore, future research should also investigate the stated dimensions.

\section{References}

Agnew, J. R. and Szykman, L. R. (2005). Asset allocation and information overload: The influence of information display, asset choice, and investor experience. The Journal of Behavioral Finance, 6(2):57-70.

Barberis, N. and Thaler, R. (2003). A survey of behavioral finance. Handbook of the Economics of Finance, 1:1053-1128.

Braha, D. (2012). Global civil unrest: contagion, selforganization, and prediction. PloS one, 7(10):e48596.

Bucher-Koenen, T. and Ziegelmeyer, M. (2011). Who lost the most? financial literacy, cognitive abilities, and the financial crisis.

Chang, Y. Y., Faff, R., and Hwang, C.-Y. (2009). Does investor sentiment impact global equity markets. In Milan EFMA meetings.

Chen, H. and Volpe, R. P. (1998). An analysis of personal financial literacy among college students. Financial services review, 7(2):107-128.

Fuertes, A.-M., Muradoglu, G., and Ozturkkal, B. (2014). A behavioral analysis of investor diversification. The European Journal of Finance, 20(6):499-523.

Giesler, M. and Veresiu, E. (2014). Creating the responsible consumer: Moralistic governance regimes and consumer subjectivity. Journal of Consumer Research, 41(3):840-857.

Grinblatt, M., Titman, S., and Wermers, R. (1995). Momentum investment strategies, portfolio performance, and herding: A study of mutual fund behavior. The American economic review, pages 1088-1105.

Harikanth, D. and Pragathi, B. (2012). Role of behavioural finance in investment decision making-a study on select districts of andhra pradesh, india. International Journal in 
Multidisciplinary and Academic Research (SSIJMAR), 1(4):115.

Hassan Al-Tamimi, H. A. and Anood Bin Kalli, A. (2009). Financial literacy and investment decisions of uae investors. The Journal of Risk Finance, 10(5):500-516.

Hilgert, M. A., Hogarth, J. M., and Beverly, S. G. (2003). Household financial management: The connection between knowledge and behavior. Fed. Res. Bull., 89:309.

Hung, A., Parker, A. M., and Yoong, J. (2009). Defining and measuring financial literacy.

Kengatharan, L. and Kengatharan, N. (2014). The influence of behavioral factors in making investment decisions and performance: Study on investors of colombo stock exchange, sri lanka. Asian Journal of Finance E Accounting, 6(1):1.

Khurshid, M. R. (2012). Overconfidence and perceived market efficiency.

Lakonishok, J., Shleifer, A., and Vishny, R. W. (1992). The impact of institutional trading on stock prices. Journal of financial economics, 32(1):23-43.

Larrick, R. P., Burson, K. A., and Soll, J. B. (2007). Social comparison and confidence: When thinking youre better than average predicts overconfidence (and when it does not). Organizational Behavior and Human Decision Processes, 102(1):76-94.

Le-Phuoc, D., Dao-Tran, M., Parreira, J. X., and Hauswirth, M. (2011). A native and adaptive approach for unified processing of linked streams and linked data. In International Semantic Web Conference, pages 370-388. Springer.

Lee, W. Y., Jiang, C. X., and Indro, D. C. (2002). Stock market volatility, excess returns, and the role of investor sentiment. Journal of banking E Finance, 26(12):2277-2299.

Lin, H.-W. et al. (2011). Elucidating the influence of demographics and psychological traits on investment biases. World Academy of Science, Engineering and Technology, 77:145-150.

Lusardi, A. and Mitchell, O. S. (2011). Financial literacy and planning: Implications for retirement wellbeing. Technical report, National Bureau of Economic Research.

Malik, S. U. and Elahi, M. A. (2014). Analysis of herd behavior using quantile regression: Evidence from karachi stock exchange (kse).

Merikas, A., Merikas, A., Vozikis, G., and Prasad, D. (2003). Factors influencing greek investor behavior on the athens stock exchange. In Annual Meeting of the Academy of Financial Services, Denver (Colorado, USA).
Muhammad, N. M. N. and Abdullah, M. (2009). Investment decision-making style: Are malaysian investors rational decision makers. Interdisciplinary Journal of Contemporary Research in Business, 1(3):96-108.

Patel, N. and Sewell, M. (2015). Calendar anomalies: a survey of the literature. International Journal of Behavioural Accounting and Finance, 5(2):99-121.

Persaud, A. (2000). Sending the herd off the cliff edge: the disturbing interaction between herding and market-sensitive risk management practices. The Journal of Risk Finance, 2(1):59-65.

Pompian, M. M. (2012). Behavioural finance and wealth management: How to build investment strategies that account for investor biases, hoboken.

Rea, L. and Parker, R. (2005). Designing and constructing survey research. San Francisco.

Samuelson, W. and Zeckhauser, R. (1988). Status quo bias in decision making. Journal of risk and uncertainty, 1(1):7-59.

Shefrin, H. (2002). Beyond greed and fear: Understanding behavioral finance and the psychology of investing. Oxford University Press on Demand.

Shefrin, H. et al. (2010). Behavioralizing finance. Foundations and Trends $\mathbb{R}$ in Finance, 4(1-2):1-184.

Shefrin, H. and Statman, M. (1985). The disposition to sell winners too early and ride losers too long: Theory and evidence. The Journal of finance, 40(3):777-790.

Shefrin, H. and Statman, M. (2000). Behavioral portfolio theory. Journal of financial and quantitative analysis, 35(2):127151.

Sukanya, R. and Thimmarayappa, R. (2015). Impact of behavioural biases in portfolio investment decision making process. International Journal of Commerce, Business and Management (IJCBM), 4(4):1278-1289.

Wermers, R. (1999). Mutual fund herding and the impact on stock prices. the Journal of Finance, 54(2):581-622.

Widdowson, D., Hailwood, K., et al. (2007). Financial literacy and its role in promoting a sound financial system. Reserve Bank of New Zealand Bulletin, 70(2).

Yates, J. F., Lee, J.-W., and Bush, J. G. (1997). General knowledge overconfidence: cross-national variations, response style, and reality. Organizational behavior and human decision processes, $70(2): 87-94$.

Zaidi, F. B. and Tauni, M. Z. (2012). Influence of investors personality traits and demographics on overconfidence bias. Institute of Interdisciplinary Business Research, 4(6):730-746. 